7.med. Genet. (1966). 3, 5 .

\title{
Juvenile Polyposis Coli
}

\author{
A. M. O. VEALE, I. McCOLL, H. J. R. BUSSEY, and B. C. MORSON
}

\section{From the Research Department, St. Mark's Hospital, London}

The term 'polyposis coli' applies to a condition of multiple polyps of the large intestine and is used synonymously with 'familial polyposis' and 'multiple adenomatosis'. The latter name emphasizes the fact that the individual polyps of this disease in no way differ from adenomas observed as solitary lesions.

The object of this paper is to describe the histopathology, clinical features, and family histories of II patients with polyposis in whom the polyps were not adenomas but had the structure of juvenile polyps. The latter are often confused with adenomas despite clear differences in pathology and behaviour.

Juvenile polyps, like adenomas, are usually present as solitary lesions, but just as adenomatous polyps may be present in large numbers (adenomatous polyposis coli), so the large intestinal mucosa may be covered with multiple polyps of the juvenile variety, henceforward called 'juvenile polyposis coli'.

Large intestinal polyposis has been described in children by Kerr (1948), Gordon, Hallenbeck, Dockerty, Kennedy, and Jackman (1957), and Hines, Hanley, Ray, and Rush (1959), but these authors, wrongly in our opinion, referred to the polyps as 'adenomas'. Castro (1955), Mallam and Thomson (1959), and Knox, Miller, Begg, and Zintel (1960) also reported cases of colonic polyposis in children, but did not describe any investigation of the family histories of their patients. A summary of the clinical features and pathology of our cases has been published elsewhere (McColl, Bussey, Veale, and Morson, 1964).

\section{Diagnosis of Juvenile Polyp}

The typical adenomatous polyp (Fig. I) has a lobulated surface appearance with intercommunicating cracks or crevices separating the lobules. In contrast the juvenile polyp (Fig. 2) is charac-

Received May 13, 1965. teristically smooth in its surface configuration. Occasionally juvenile polyps have a papillary or lobulated surface pattern which makes any precise distinction between the two types of tumour unreliable on simple inspection alone. However, the cut surface of juvenile polyps usually shows multiple cysts filled with mucin (Fig. 2), hence the name 'retention polyp' sometimes applied to these tumours. Cystic changes in true adenomas are exceptional. The stalks of juvenile polyps appear no different from those of adenomas, except that in surgical specimens containing multiple juvenile polyps there may be some stalks without tumours.

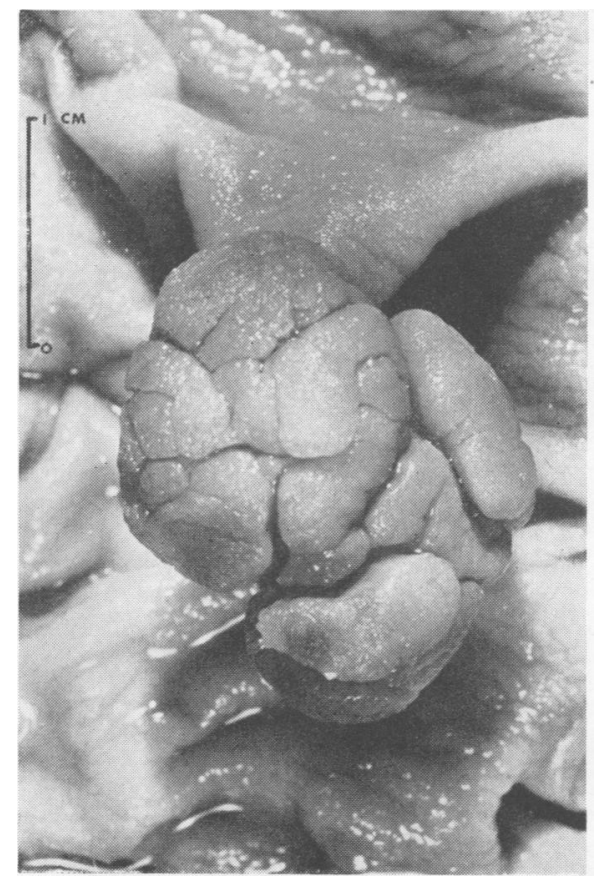

Fig. I. Adenomatous polyp: the tumour is composed of lobules separated from one another by intercommunicating crevices. 


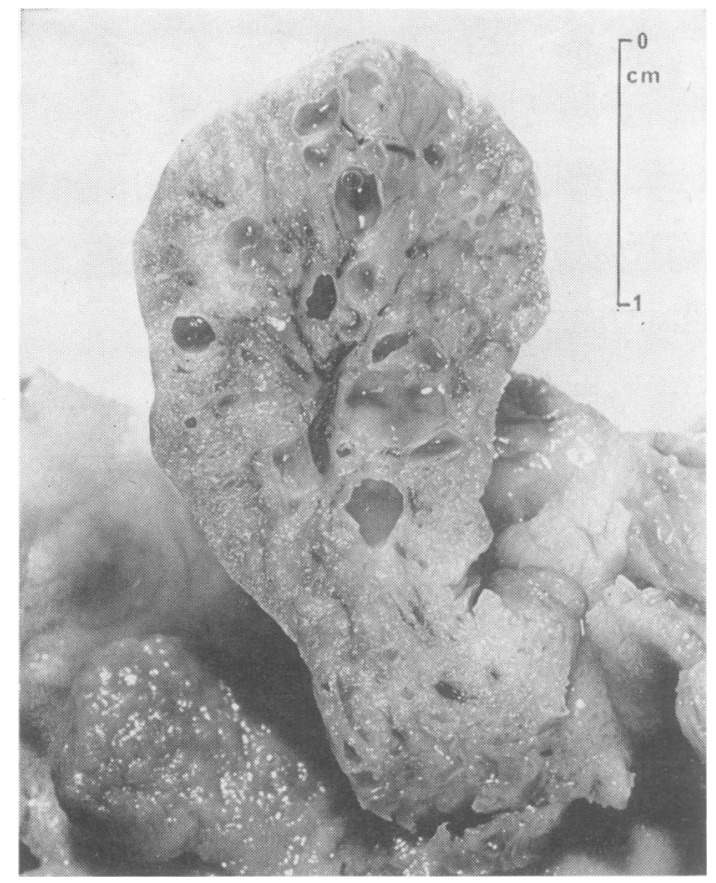

FIG. 2. Juvenile polyp: the surface of the tumour is characteristically smooth in its surface outline. The cut surface shows numerous cysts filled with mucin.
In such cases it may be presumed that the tumoun

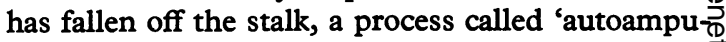
tation', which is characteristic of juvenile polyps. (Lane, 1865). A possible explanation for this behaviour is the absence of any participation byo the muscularis mucosa in the structure of juveniles polyps.

The size of juvenile polyps varies from smalb sessile nodules a few millimetres in diameter to pedunculated tumours about $3 \mathrm{~cm}$. across. Theys are often very haemorrhagic in appearance, which $\vec{p}$ could be due to infarction from twisting of theirpedicles.

Microscopically, both juvenile and adenomatouspolyps have an epithelial and a connective tissue element. The muscularis mucosae seems to play. no part in the growth of juvenile polyps, but in adenomatous polyps smooth muscle fibres areo sometimes found in the stroma. In an adenoma the proliferating epithelial tubules are packed closely together, being separated by supporting tissue which is morphologically similar to normaB lamina propria (Fig. 3 and 4). The epithelium shows a diminution in the number of goblet cells crowding of the nuclei with much hyperchromatism; and an increased number of mitotic figures, alb features that are characteristic of a neoplasm. Ins contrast the epithelial lining of the tubules in

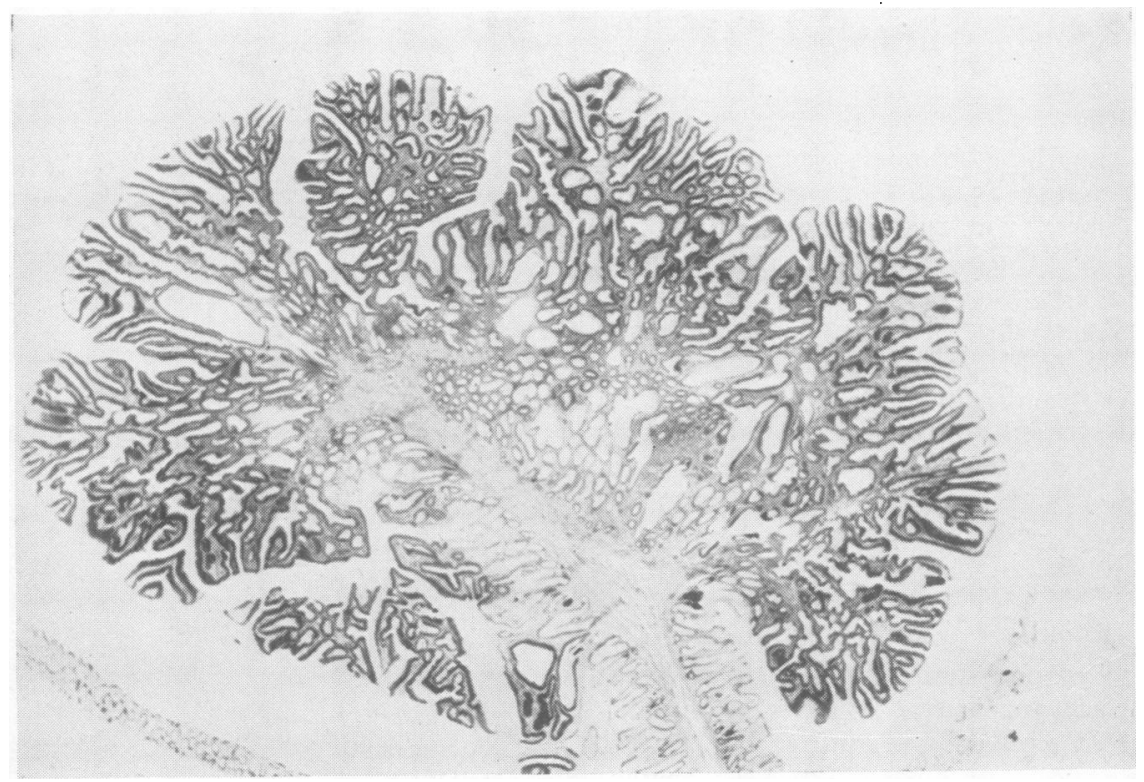

FIG. 3. Adenomatous polyp: the proliferating tubules are packed closely together and there is a well-marked lobulated surface configuration. (H. and E. $\times$ 5.) 


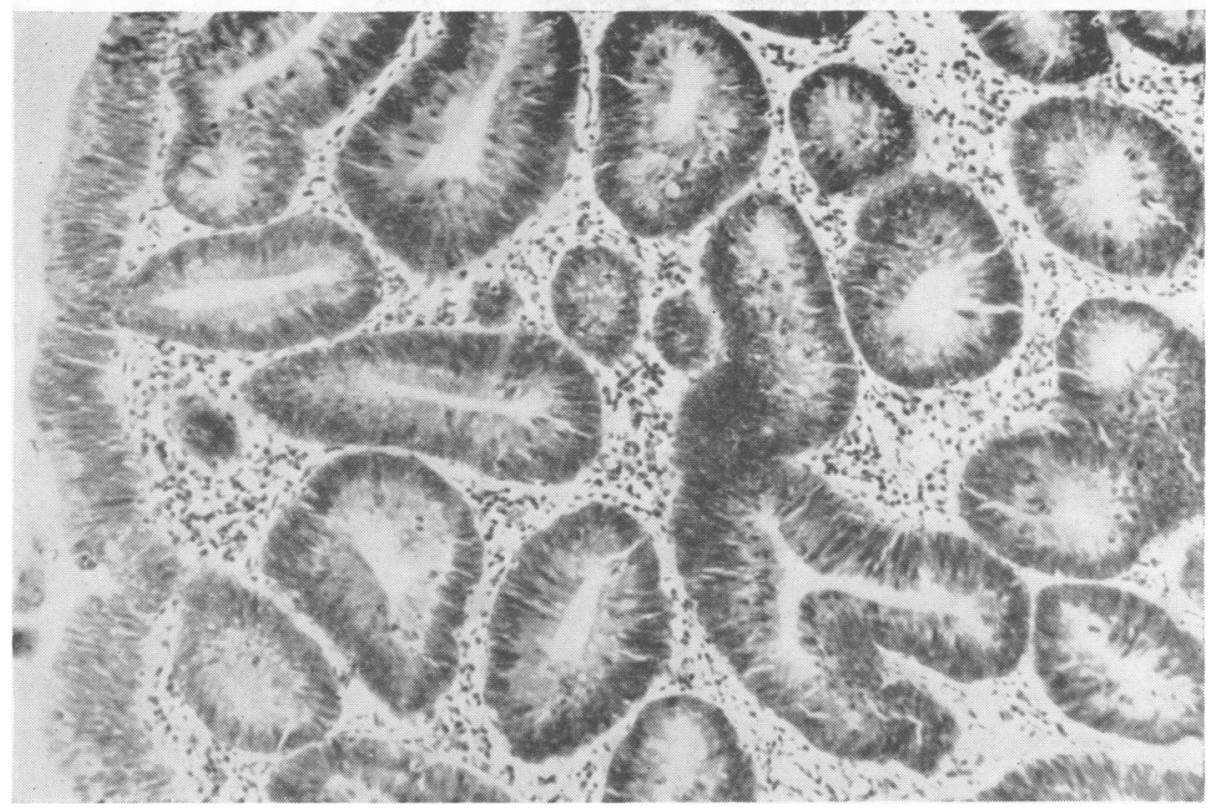

FIG. 4. Adenomatous polyp: the closely packed epithelial tubules show diminution in the number of goblet cells, crowding of nuclei, hyperchromatism, and an increased number of mitoses. The tubules are separated by lamina propria which is qualitatively and quantitatively normal. (H. and E. $\times$ IOO.)

juvenile polyps (Fig. 5 and 6) consists of cells that show little sign of increased nuclear activity such as hyperchromatism and mitosis, although there may be some diminution in the number of goblet cells. The tubules readily become dilated by retained mucus leading to flattening of the epithelial lining.

The most striking feature of juvenile polyps is the greatly increased amount of supporting connective tissue compared with adenomas. The epithelial tubules are widely separated by a fine areolar network of reticulin fibres and connective tissue cells containing a sprinkling of lymphocytes and plasma cells.

True bone has been reported in the stroma of juvenile polyps (Todd, 1963; Marks and Atkinson, 1964), probably the result of metaplasia, and lymphoid tissue with central germinal follicles is regularly seen.

The surface of juvenile polyps may be covered by a single layer of normal-appearing columnar epithelium. This is readily breached, probably by trauma from the movement of faeces, leading to secondary infection of the tumour. In such cases, there is a greatly increased number of lymphocytes and plasma cells in the connective tissue and even micro-abscess formation. Haemorrhage into the substance of these tumours also causes changes that readily obscure the correct diagnosis. In particular infarction from twisting of the pedicle may convert the juvenile polyp into a shadow of its former self.

In those juvenile polyps that have a pronounced papillary surface appearance the microscopical structure shows some variation from that usually seen. The excess of supporting connective tissue is not so great, though the tubules are still much more widely spaced than in normal mucosa or in adenomatous polyps. In such cases, however, it can be seen that the epithelial cells are normal and show little evidence of hyperplasia or neoplasia. The diagnosis of juvenile polyp rests not only on the excess of connective tissue, but also on the absence of those epithelial changes that are characteristic of benign neoplastic proliferation.

\section{Materials and Methods}

The pathology of 145 patients with polyposis coli in the records of the research department at St. Mark's Hospital was reviewed. In 6 patients the polyps had the microscopical structure of the juvenile type. A 
Veale, McColl, Bussey, and Morson

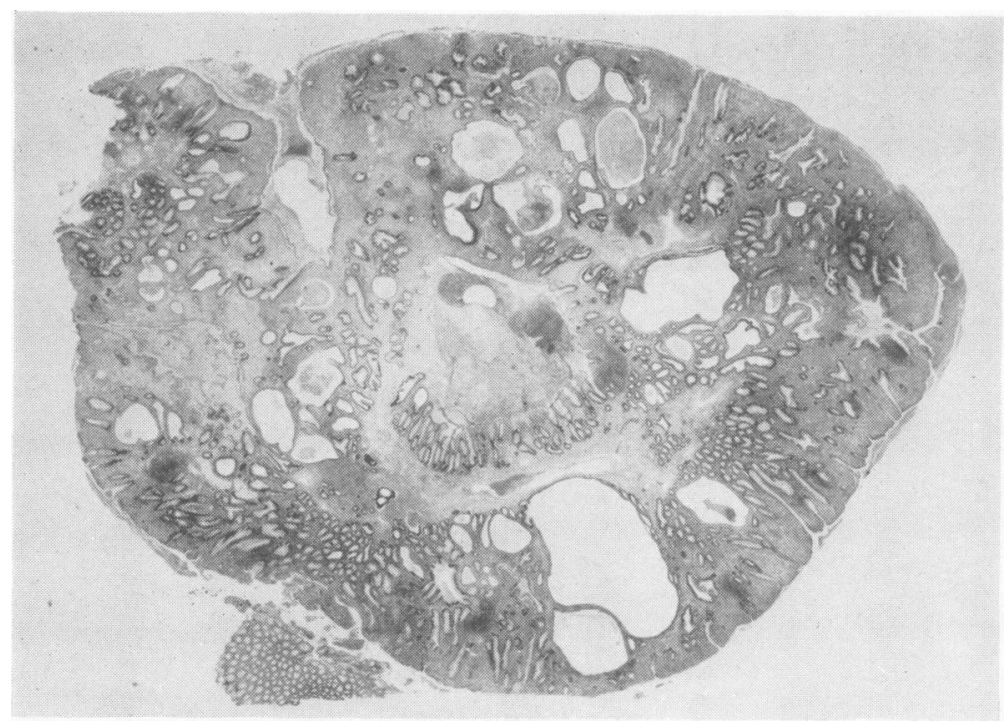

Fig. 5. Juvenile polyp: the tumour has a smooth outline and its substance contains numerous cystic spaces. (H. and $\mathrm{E} . \times 4$.)

seventh patient, for whom there is no histological confirmation (Case III.3, Family 2), was accepted as suffering from juvenile polyposis on clinical and followup evidence. These 7 patients belonged to 4 different families.
In addition 4 other cases of juvenile polyposis were obtained from the Royal Marsden Hospital (I) and Guy's Hospital (3). These occurred in 4 families, an thus there was a total of I I patients from 8 families for study.

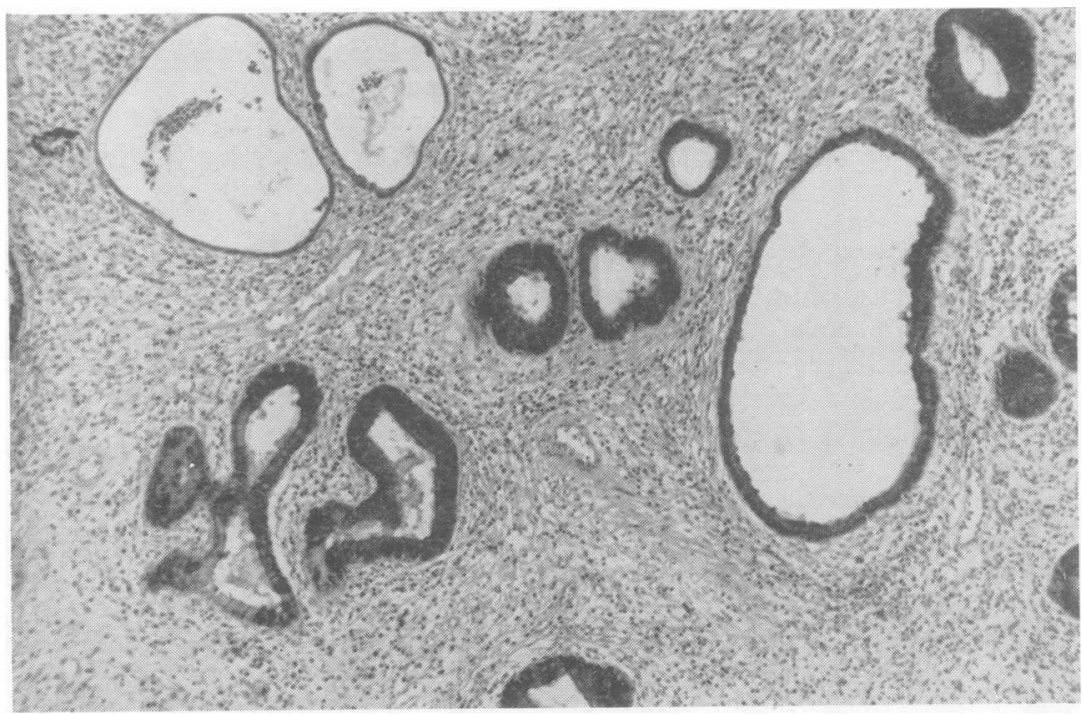

FIG. 6. Juvenile polyp: the epithelial tubules are widely separated by the supporting connective tissue which has a 'mesenchymal' appearance unlike normal lamina propria. There is cystic dilatation with flattening of the epithelial lining but no sign of epithelial hyperplasia. (Mucicarmine. $\times$ 68.) 


\section{Case Histories}

Case I (female, aged 18 months). She passed bright red blood with her stools at the age of 18 months. Examination revealed three rectal polyps which could easily be made to prolapse through the anus. The tumours were plucked off with the fingers. Two more polyps were removed through the sigmoidoscope and barium enema examination indicated others in the descending colon. Intermittent rectal bleeding continued, and two more polyps were removed sigmoidoscopically at the age of 4 . A year later laparotomy showed 2 polyps in the terminal ileum, one each in the caecum and ascending colon, 2 in the transverse colon, and 4 in the descending colon. At the age of 7 years 12 more rectal polypi were removed, since when there has been no further bleeding for the past three years.

Histological examination of all the polyps removed, including those from the small intestine, showed them to be juvenile polyps.

Case 2 (female, aged I3 years). She was admitted to hospital when she was 13 years old for appendicectomy when the caecum was found to be subhepatic. Abdominal pain continued, and laparotomy two weeks later showed oedema of the caecum thought to be due to intussusception; a right hemicolectomy was performed. The resected specimen contained numerous polyps, particularly in the caecum, all of which had the structure of juvenile polyps. After discharge from hospital she began to pass blood and mucus per rectum with prolapse of polyps on defaecation. Tenesmus became a prominent symptom and the patient was admitted to hospital again when 20 years old. She was thin, pale, and weighed only $86 \mathrm{lb}$. (39 kg.). Sigmoidoscopy showed scores of polyps ranging in size from 0.5 to $3 \mathrm{~cm}$. in diameter. They were particularly numerous in the rectum but less frequent in the lower sigmoid colon. Double contrast barium enema demonstrated polyps from the mid part of the descending colon to the pelvic colon. Laboratory investigations revealed low levels of serum potassium, reduced total plasma protein, and porphyria.

Fifteen polyps were removed through two colotomies in the sigmoid and ascending parts of the colon. The rectum was so thickly covered by polyps that no normal mucosa could be seen. The largest polyps were found in the lower rectum and several of these prolapsed out of the anus on long thin strap-like stalks. Histologically they were all juvenile polyps.

Case 3 (female, aged 4 years). She was the product of a full-term birth, weighing I I $\frac{1}{2} \mathrm{lb}(5 \cdot 2 \mathrm{~kg}$.). Her head was said to be disproportionately large and her left foot had a sixth toe. At 18 months she began to pass a little blood and on one occasion a small polyp. The bleeding increased, with frequent prolapse of polyps, diarrhoea, and abdominal pain during defaecation.

On examination the most striking feature was her large head. Hypotonia was present in all limbs with weakness of the pelvic and shoulder girdles. The knee and ankle-jerks were absent. She had an exaggerated lumbar lordosis with a protuberant abdomen. There was marked clubbing of the fingers and toes. The rectum was full of polyps. A hypochromic anaemia of $6 \mathrm{~g} . /$ I00 $\mathrm{ml}$. was corrected by blood transfusion, but her diarrhoea became more severe. A diagnosis of hypertelorism, amyotonia congenita, and adenomatous polyposis was made.

Ileostomy and total proctocolectomy were carried out. A total of 80 polyps were scattered throughout the excised colon. Histologically they were all juvenile polyps. The patient made a good recovery from the operation but died two years later, the cause of death being given as inanition, polyposis, and hydrocephalus.

Case 4 (male, aged 2 years). He was born with an umbilical faecal fistula and a Meckel's diverticulum, and was kept under observation for a mild communicating hydrocephalus. Rectal bleeding was first noticed at the age of 2 years and sigmoidoscopy showed a polyp at $15 \mathrm{~cm}$. At laparotomy 3 polyps were removed from the caecum and 2 from the descending colon, but others were palpable in other parts of the colon. Malrotation of the gut was present, the transverse colon being posterior to the jejunum. The left testis was in the abdomen and the right in the inguinal canal.

The following year there was a recurrence of the rectal symptoms accompanied by prolapse of polyps. At the age of 4 several polyps were removed through the sigmoidoscope. Over subsequent years his health remained good apart from an iron deficiency anaemia of $8 \mathrm{~g}$./100 ml. However, his symptoms became more severe and sigmoidoscopy and radiological examination revealed further polyps. It was decided to resect the colon as he was thought to have adenomatous polyposis coli. Colectomy with ileo-rectal anastomosis was carried out, and a single polyp was excised from the ileum.

The operation specimen showed a few polypoid excrescences in the ileum. Pedunculated polyps ranging in size up to $2 \mathrm{~cm}$. in diameter were scattered throughout the colon. The cut surface of the larger tumours was cystic. Sections of the nodules in the terminal ileum showed them to be hypertrophic Peyer's patches. The single ileal polyp as well as the colon polyps were all of the juvenile type.

The patient is now aged Io and is in good health. A year ago several polyps were seen on sigmoidoscopy and removed.

Case 5 (female, aged 13 years: III.2 in Pedigree I (Fig. 7)). She first passed blood per rectum at the age of 13. Polyps prolapsing through the anus were thought to be haemorrhoids. Sigmoidoscopy at the age of 18 showed many polyps in the rectum. The two largest were excised and the remainder destroyed by diathermy. During the ensuing 30 years another 10 polyps were removed, the last being at the age of 52 . They all had the histology of the juvenile variety.

Case 6 (female, aged 8 years: III. 3 in Pedigree I (Fig. 7), sister of Case 5). At the age of 8 years she 

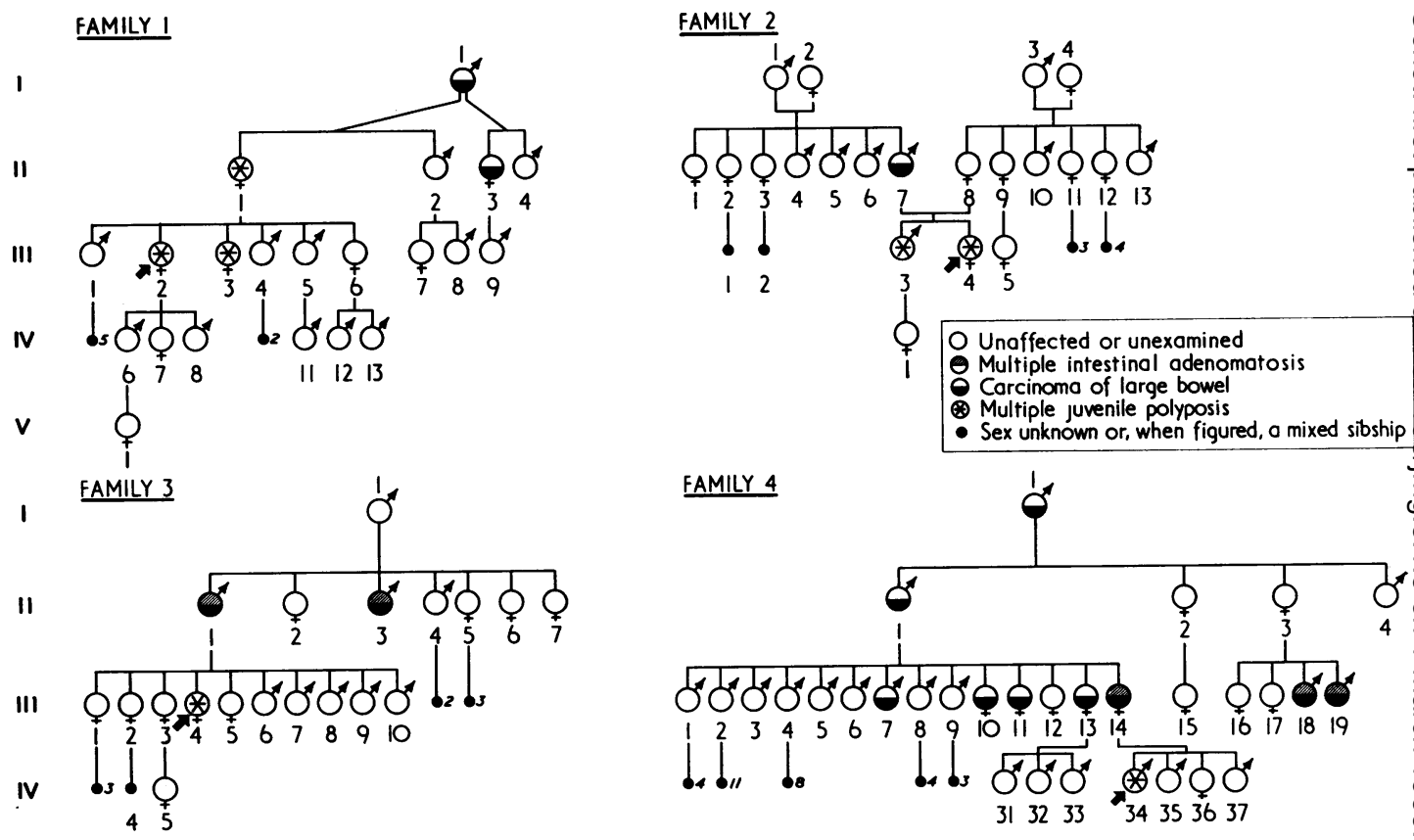

FIG. 7. Pedigrees of Families I, 2, 3, and 4 .

began passing mucus in her stools, followed later by bleeding diarrhoea and prolapse of polyps. The patient was thought to have adenomatosis coli. At 19 years many polyps were seen on sigmoidoscopy and removed. These were all found to be juvenile polyps. Barium enemas at the age of 38 and 5o years were normal.

Case 7 (female, aged 40 years: II.I in Pedigree I (Fig. 7), mother of Cases 5 and 6). This patient never complained of any symptoms but was examined at the age of 40 because her daughter (III.2) had polyposis. Two rectal polyps were found and removed. During the following 2 years 7 more were excised, since when she has been clinically and radiologically normal. Histologically all the polyps were of the juvenile type.

Case 8 (female, aged 20 years: III. 4 in Pedigree 2 (Fig. 7)). She first presented at the age of 20 with a history of prolapsing polyps and passage of mucus for 'some years'. Sigmoidoscopy showed multiple polyps ranging in size from 5 to $25 \mathrm{~mm}$. A diagnosis of adenomatous polyposis was made and a colectomy with ileorectal anastomosis was performed. During the subsequent 37 years small rectal polyps have appeared at irregular intervals and have been removed. All the tumours have had the typical structure of juvenile polyps.

Case 9 (male, aged 12 years: III.3 in Pedigree 2
(Fig. 7), brother of Case 8). Seen at St. Mark's Hospita? in 1910 with multiple rectal polypi, some of which ha prolapsed. No histology is available, but the description of the clinical picture certainly suggests juvenile poly posis. Scores of polyps were removed together with 3-in. $(7.6 \mathrm{~cm}$.) length of rectal mucosa and others were destroyed by diathermy. Further polyps were removed at intervals during the following 8 years, but the patient had no rectal trouble thereafter. He die $\vec{P}$ from a heart attack at the age of 63 .

Case 10 (female, aged Io years: III.4 in Pedigree $\frac{\partial}{3}$ (Fig. 7)). She first had rectal bleeding when 4 years old. Barium enema examination and sigmoidosopy at the age of to showed many polyps which bled readily on. contact. Colectomy and ileo-rectal anastomosis werre performed. During the operation a lymphangioma was excised from the mesentery of the ileum.

The operation specimen showed a total of 130 tumours varying in size from tiny pinpoint dome-shaped mucosat elevations up to tumours $2 \mathrm{~cm}$. in diameter on long stalks. All the polyps were deeply haemorrhagic and friable some had a smooth surface while others were lobulated In the caecum, where the tumours were most numerous, there were many branching stalks without polyps, as the latter had sloughed off. The polyps examine $P$ microscopically were all of the juvenile type with muc secondary infection and haemorrhage. 
Case II (male, aged 8 years: IV.34 in Pedigree 4 (Fig. 7)). This boy had rectal bleeding, diarrhoea, and prolapsing polyps at the age of 5. When 8 years old he was admitted to hospital with severe abdominal pain, and laparotomy revealed polyps in the caecum. Polyps were also seen on sigmoidoscopy, and an x-ray examination a year later confirmed their presence throughout the colon. At the age of 9 , colectomy with ileo-rectal anastomosis was performed.

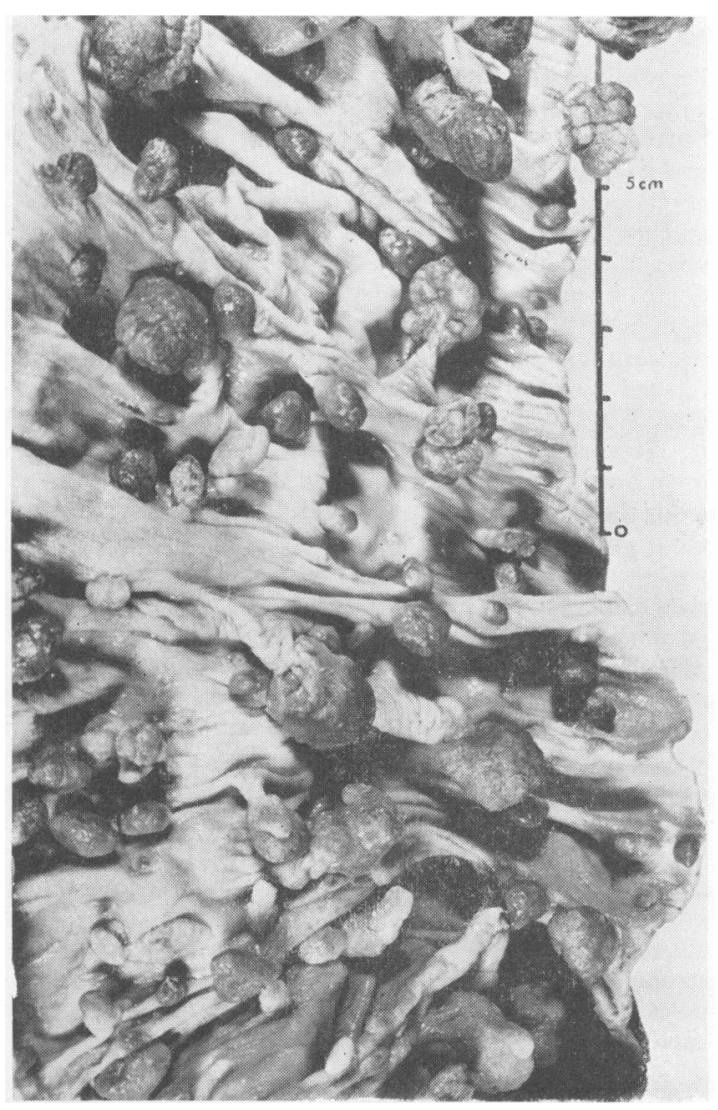

FIg. 8. Juvenile polyposis coli, Case Ir. The mucous membrane is covered with numerous pedunculated polyps, most of which have a smooth surface configuration.

A total of 235 polyps was scattered over the mucosa of the excised specimen, but mainly in the caecum and ascending colon (Fig. 8). The tumours had naked-eye appearances and microscopical characters similar to those described in Case 10. Since the operation a few small rectal polyps have been removed. The patient died suddenly at the age of 17 , probably from acute intestinal obstruction.

\section{Family History}

The II cases described above come from 8 families, 3 from one family, and 2 from another, the remaining 6 being solitary examples. In 4 of these 6 families no other case of bowel disease was discovered in spite of inquiries involving a total of 140 family members. The histories of the remaining 4 families are as follows.

Family I (Fig. 7). It has already been mentioned that Cases 5 and 6 (III.2 and III.3) are sisters and that Case 7 (II.I) is their mother. The maternal grandfather (I.I) died from cancer of the rectum aged 57, but no information is available about either of his wives. His daughter (II.3) by his second marriage died from carcinoma of the colon at 32 years of age. No bowel trouble was found in any other member of the family.

Family 2 (Fig. 7). In this family both brother and sister (III.3 and III.4) had juvenile polyposis (Cases 8 and 9). Their father (II.7) was treated at St. Mark's Hospital for an inoperable cancer of the rectum.

Family 3 (Fig. 7). The propositus (III.4, Case I0) has a sister (III.3) who was found to have 3 rectal polyps at the age of II years, one brother (III.6) who had a small polyp at 5 years, and another (III.7) who had 2 polyps at the age of 4 . Unfortunately, no histology is available of any of these tumours.

The father of the propositus (II.I) is known to have died aged 46 from cancer of the rectum and adenomatosis coli, as did also his brother (II.3) at the age of 33 .

Family 4 (Fig. 7). In this family, the mother of the propositus (III.I4) and 4 of her I3 sibs died from intestinal cancer. Her father (II.I) and grandfather (I.I) and two cousins (III.I8 and III.I9) are also said to have died from the same cause. Polyposis was present in the mother and her two cousins, but its nature is unknown as no histological material is available for study. The general pattern, however, is that of adenomatosis.

The histories of the 8 families may be summarized as follows. In 4 there was a single case of juvenile polyposis but no evidence of bowel disease in other members of these families. In the other 4 families intestinal cancer was also present, being associated with multiple adenomatosis in 2 families, and with more than one case of juvenile polyposis in the other 2 families.

\section{Discussion}

Genetics. There are two families in which more than one person is affected with juvenile polyposis (Families I and 2); in addition there are 3 families ( 1,2 , and 4 ) in which a number of relatives are known to have died from cancer of the colon or rectum. In Family 3 the father of the propositus suffered from adenomatous polyposis and died from cancer of the rectum. All 4 families contain other relatives known to have died from 
large bowel cancer but in whom the diagnosis of adenomatous polyposis was not made or cannot be confirmed with certainty. It is noteworthy that at one time each of these 4 families was thought to be suffering from adenomatous polyposis but was included in the juvenile polyposis series when the histology of the polyps was reviewed. Of especial significance is Family 3 in which the initial ascertainment was through II.I who was affected with classical adenomatous polyposis and cancer of the rectum. His daughter III.4 began to have bowel symptoms at the age of 4 years and was later treated by colectomy and ileo-rectal anastomosis. It was only after some years that the significance of the histology of the polyps in III.4 was appreciated.

The simplest explanation for the appearance of multiple juvenile polypi would be that this is a manifestation of the polyposis gene in children. A necessary corollary of this hypothesis would be that as these children grow older they would cease to make juvenile polyps and that adenomas would begin to appear in increasing numbers. Such a change from juvenile polyposis to adenomatous polyposis has never been observed in any of the young patients with polyposis who have been treated at St. Mark's Hospital.

A further explanation is that unknown environmental factors modify the action of the polyposis gene and produce juvenile polyps instead of adenomas. It is not clear how genetic or environmental factors could account for the high incidence of gross congenital abnormalities in the cases of juvenile polyposis reported here.

If there is a separate gene for juvenile polyposis it appears to have been passed from parent to offspring in a number of cases, but the difficulties of explaining the family history of bowel cancer are considerable. Histologically juvenile polyps present none of the features of a pre-cancerous condition. Furthermore the appearance in one family of proved adenomatous polyposis and the strong family history of bowel cancer in three other families must be regarded as more than a coincidence.

Veale (1962) examined 76 families with adenomatous polyposis collected at St. Mark's Hospital over a period of 40 years. Correlations between relatives of various age parameters connected with polyposis (age at appearance of polypi, age at onset of symptoms, age at death from cancer) all showed consistent values near +0.5 for correlations between sibs (brothers and sisters); and values of zero between affected parents and offspring. In the absence of significant environmental influences the values of both correlations are expected to be +0.5 . Environment was not thought to be important in adeno- matous polyposis as the average age for onset of sym toms was 29 years, and for death from cancer 4I years. At these ages differences in environment between sibs are likely to be just as great as those between pareris and children. Consequently some other explanation $6 f$ the absence of a parent-child correlation was requirea. Later Veale (1965) increased the number of familes studied to 102 with confirmation of the previous resuless. A genetic model involving three allelic genes was proposed. The genes were:

'P' the adenomatous polyposis gene; ' $p$ ' the 'polyd' gene; ' + ' the normal gene.

Persons with polyposis could thus have two possibfe genotypes, $\mathrm{Pp}$ and $\mathrm{P}+$ (a third genotype $\mathrm{PP}$ is possibse but will be so rare that it can safely be neglected). $9 \mathrm{tt}$ was proposed that persons of genotype $\mathrm{Pp}$ suffered from severe adenomatous polyposis with early age of onset and early death from cancer. Persons of genotype $\mathrm{P} \phi$ were thought to have a later age of onset and a later death from cancer. Evidence was produced to show that persons with polyposis probably consisted of two overlapping distributions. The genes ' $p$ ' and ' + ' ace termed modifying alleles, as the action of the polyposis gene is modified according to which allele accompanigs it. Since an affected child receives the polyposis geof from his affected parent, the modifying allele must coine from the normal parent who will have one of three poo sible genotypes: $\mathrm{pp}, \mathrm{p}+$, or ++ . There is thus în reason why the genotype of the affected children should necessarily be the same as that of their affecteng parent. The parent-child correlation is thus zero. $\mathbb{D}_{t}$ can also be shown that under these circumstances the sib-sib correlation will be +0.5 for all frequencies of the ' $p$ ' and ' + ' genes in the general population. An estimate of the possible frequency of the 'p' gene 晋 the population is possible if it is supposed that persons of genotype 'pp' are those people in whom isolated adenomas of the colon and/or rectum appear. elaboration of this genetic model allows adenomatoss polyposis families, i.e. the few families in which isolated adenomas appear to be inherited, and families with $\mathcal{O}_{2}$ strong history of bowel cancer in the absence of polyposis, to be included in a single genetic theory which is capable of further confirmation.

By an extension of this model it is possible include the families in which juvenile polyposf has appeared. It is now necessary to postulate 3 further allele which so modifies the action of the polyposis gene that juvenile polypi are produced instead of adenomas. The following polyposis genotypes are now possible:

Pp : adenomatous polyposis with early onset.

$\mathbf{P}+$ : adenomatous polyposis with late onset. 0

$\mathrm{Pj}$ : juvenile polyposis.

Among the population without polyposis there w 
TABLE I

POSSIBLE CLINICAL EFFECTS FOR DIFFERENT GENOTYPES

\begin{tabular}{|c|c|}
\hline Genotype & Possible Clinical Effect (Phenotype) \\
\hline $\left.\begin{array}{l}++ \\
\mathbf{j}+ \\
\mathbf{p}+ \\
\mathbf{p i} \\
\mathbf{p p} \\
\mathbf{j i}\end{array}\right\}$ & $\begin{array}{l}\text { Normal } \\
\text { Probably both normal } \\
\text { ?? Isolated adenomas and/or juvenile polyps ?? } \\
\text { Isolated adenomas } \\
\text { Isolated juvenile polyps }\end{array}$ \\
\hline
\end{tabular}

be 6 possible genotypes. In Table I we sugges possible clinical effects for the different possibilities. The term 'isolated' is here taken to mean the occurrence of a single polyp or just a few (e.g. less than 10) so that the question of multiple polyposis would not ordinarily arise. Unfortunately we cannot estimate the frequency of persons of the different genotypes without some knowledge of the relative frequencies of the genes ' $p$ ', ' $j$ ', and ' + '. The frequency of persons with isolated adenomas of the colon and rectum increases with the age of the population studied. In persons over the age of 40 the incidence is commonly reckoned to be in the region of $10 \%$ so that we may assume that this $10 \%$ is represented by the persons of the 'pp' genotype. Unfortunately, no estimate of the proportion of children with isolated juvenile polypi is available, and an accurate estimate may not even be possible. It is reasonably certain, however, that the proportion of children affected is considerably less than $10 \%$ and is probably even less than $1 \%$. If we assume that the frequency of persons carrying the ' $j$ ' gene is low, we could expect that in a small proportion of adenomatous polyposis families, with most of the affected persons showing polyposis and cancer, an occasional person would develop juvenile polyposis even though one parent appeared to have adenomatous polyposis (e.g. Family 3). If the normal parent is homozygous for the ' $j$ ' gene, then all children in the sibship who receive the polyposis gene will develop juvenile polyposis (e.g. Family 2). Much more commonly, the normal parent will be heterozygous for the ' $j$ ' gene (i.e. either pj or $j+$ ), so that in such sibships half the children receiving the polyposis gene will develop juvenile polyposis while the other half will develop adenomatous polyposis. This situation has not yet been observed, so that confirmation, or otherwise, of this genetic model must await the study of families in which juvenile polyposis and adenomatous polyposis are present in sibs.

The occurrence of 4 cases of juvenile polyposis without any family history of polyposis or cancer of the bowel seems to require some explanation. Isolated cases of adenomatous polyposis are well known, and it has been suggested that such cases are non-familial. The writers do not agree with this hypothesis. Veale (1962) has shown that mutation of a hitherto normal gene to the polyposis gene is required in order to maintain the frequency of the condition at its observed level in the population. Isolated cases (mutations) are seen to occur with just that order of frequency that independent calculations lead us to expect. There is thus no necessity to postulate the existence of a nonfamilial form of adenomatous polyposis. Such cases are more correctly regarded to have arisen as a result of mutation, and these persons can be expected to pass the condition on to half of their offspring. This has been observed to happen with a number of cases which were at first regarded as isolated and 'non-familial'.

Since mutation to the ' $P$ ' form of the gene is thought to occur, this will from time to time take place in persons carrying one or two ' $j$ ' genes, so that the new genotype will be ' $\mathrm{Pj}$ ' and juvenile polyposis will develop. The present series of juvenile polyposis cases was obtained by reviewing the histology of adenomatous polyposis families and from a search for children affected with 'polyposis'. In no sense can this investigation be regarded as a population survey, so that no conclusion can be drawn with respect to the relative incidence of cases with and without family history.

Sex Ratio in Juvenile Polyposis. Three males and eight females were affected. This is not a statistically significant deviation from the hypothesis that the sexes are equally affected. Additional cases will have to be collected before any conclusion can be drawn.

Natural History. Very little is known of the course of juvenile polyposis, but II.I (Family I) is at present alive and well aged 75 . No person with adenomatous polyposis who has attained this age without developing carcinoma is known to the writers, so that confirmation is obtained of the histological evidence that the risk of malignancy is low.

The age of onset of symptoms in patients with juvenile polyposis has already been mentioned, but a striking difference is found if the patients are divided into two groups on the basis of the presence or absence of a family history of large bowel pathology. In those patients with no family history, the age at onset of symptoms is 4.5 years, whereas in those with a family history the age is 9.5 years. This latter figure excludes the one patient who has 
never had any symptoms. A similar difference in the age at onset of symptoms was noted for adenomatous polyposis when isolated cases of polyposis were compared with the propositi of families in which other cases were found (Veale, 1962). In the isolated cases symptoms appeared at an average age of 23 years and at 29 years in the others. The genetic interpretation of these observations is that in those families where affected parents are surviving to pass their abnormal polyposis gene on to their children, they survive by virtue of the fact that their total genetic background (genome) favours their continued existence. Natural selection thus tends to perpetuate those genomes upon which abnormal genes have the least effect. When mutation occurs the genome without previous experience of the abnormal gene will be less well adapted to its effects and an average earlier and more severe effect can be expected. Consequently, the earlier age of onset in those cases without a family history can be interpreted as evidence in favour of mutation.

Congenital Anomalies. No satisfactory explanation of the various congenital anomalies found in 3 of these patients is at present suggested. It is curious that the patients with congenital anomalies are the ones without a family history of polyps or intestinal cancer.

Pathology. Whatever the nature of juvenile polyps the microscopical appearances are quite distinctive compared with adenoma (Roth and Helwig, 1963). The latter is a neoplasm of the intestinal epithelium, whereas the juvenile polyp is certainly non-neoplastic. It has been postulated elsewhere (Morson, 1962a, b) that the juvenile polyp is a hamartoma or malformation of the connective tissue element of the intestinal mucosa without the participation of the muscularis mucosae. This could explain the generally accepted view that juvenile polyps have no pre-cancerous potential (Knox et al., 1960). However, a number of authorities, notably Roth and Helwig (1963), believe they have an inflammatory origin.

There is some evidence in support of the concept that these tumours are hamartomas. First, the polyps are mostly found in babies and young children with a decreasing incidence as age advances. Secondly, associated congenital abnormalities were present in 4 of the II patients reported here (Table II). Lastly, the histopathology is usually distinctive and unlike the neoplastic types of tumour, such as adenoma and villous papilloma or indeed the inflammatory polyps of ulcerative colitis

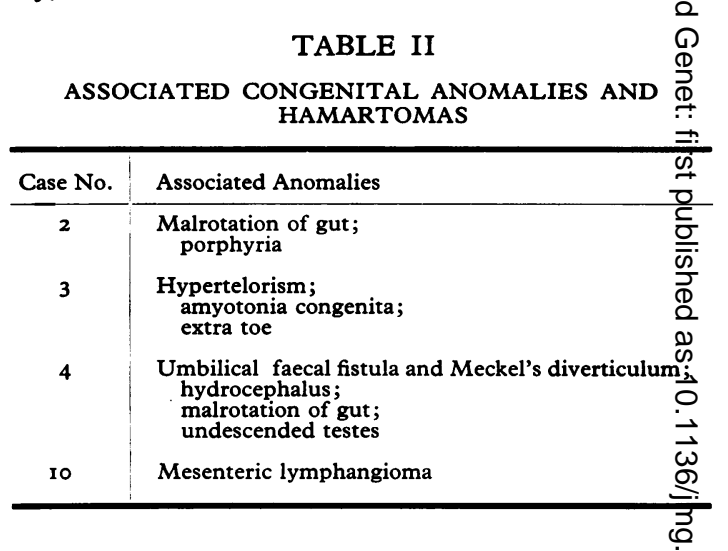

and other diffuse mucosal inflammations of the large intestine.

Willis (1958) defined hamartoma as a primaroily non-neoplastic malformation characterized by an abnormal mixture of tissue indigenous to the part with an excess of one or more of these. In juverille polyps it is the connective tissue element of the mucosa or lamina propria which appears to undergo excessive growth. Willis also allows the use of fhe term for an inborn tissue anomaly which manifessts itself by excessive growth during postnatal matumation. In some of our cases reported here as wellsas in others seen recently juvenile polyps have c. $\overline{\text { A }}$ tinued to appear during adult life after the inififal removal. This tendency to recurrence is Rot

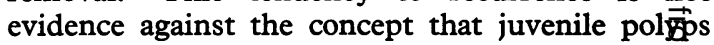
are hamartomatous. Research on epithelial Eell renewal in recent years (Leblond and Steve魚s, I948; Creamer, Shorter, and Bamforth, I98. ; Gastroenterology, 1962) has shown beyond question that the intestinal epithelium throughout postnital life is a highly dynamic structure which replaces its cell population every few days. Nor should we presume that the supporting structure of ghe mucosa or lamina propria is wholly inert, though it is likely that its turnover rate is slower than the epithelial element. The pathogenesis of juvenile polyps might well be explained by an inborn (probably genetic) tissue anomaly which expresses itself in a morphological pattern that does not predispose to malignant change (i.e. it is non-neoplastic), in contrast to adenomatous polyposis coli in which the gene expresses itself in the form of a benign neoplastic state of the intestinal epitheliam prone to malignant degeneration.

Clinical Features. The passage of bright red blood per rectum occurred in 9 out of II patiegits and was the commonest presenting symptom (Table III). This was often accompanied goy 
TABLE III

\begin{tabular}{l|c|c}
\hline \multicolumn{1}{c|}{ Symptoms } & $\begin{array}{c}\text { No. of } \\
\text { Patients }\end{array}$ & $\begin{array}{c}\text { Presenting } \\
\text { Symptoms }\end{array}$ \\
\hline $\begin{array}{l}\text { Rectal bleeding } \\
\text { Prolapse of polyps } \\
\text { Mucus } \\
\text { Diarrhoea }\end{array}$ & 9 & 6 \\
Abdominal pain & 8 & 3 \\
& 4 & - \\
& 2 & - \\
\hline
\end{tabular}

mucus and diarrhoea. Two patients underwent emergency laparotomy for right-sided abdominal pain. These symptoms are not uncommon in adenomatous polyposis, however, and may herald the onset of malignant change. Prolapse of polyps out of the rectum is a common feature of juvenile polyposis but rare in the adenomatous variety. One patient had no symptoms. The average age of onset of symptoms was 6 years, and 8 of the II patients were female. In contrast the average age of onset of symptoms in adenomatous polyposis is approximately 30 years and the sexes are equally affected (Veale, 1962).

The appearances of these juvenile polyps was characteristic. They were bright red, smooth, glistening spheres which bled readily on contact. The size varied from 3 to $30 \mathrm{~mm}$. in diameter and most were pedunculated. They could be made to prolapse out of the rectum and could be plucked off the rectal wall with ease and with only a minimum of bleeding. Spontaneous passage of polyps also occurred. In contrast adenomatous polyps are usually dark red and lobulated, do not bleed easily on contact, cannot be readily plucked off, and are not usually passed spontaneously.

Sigmoidoscopy and barium enema radiographs indicated the extent of the disease, but the number of polyps present was usually underestimated. All II patients had rectal polyps, and in 4 they were limited to the rectosigmoid and did not exceed 40 (see Table IV). In the other 7 patients the polyps were found throughout the colon, mainly gathered

\section{TABLE IV}

DISTRIBUTION OF JUVENILE POLYPS

\begin{tabular}{|c|c|c|c|}
\hline & Site & $\begin{array}{c}\text { No. of } \\
\text { Cases }\end{array}$ & $\begin{array}{l}\text { No. of } \\
\text { Polyps }\end{array}$ \\
\hline \multicolumn{2}{|c|}{ Recto-sigmoid only } & 4 & $10 / 40$ \\
\hline \multirow[b]{2}{*}{$\begin{array}{l}\text { Throughout } \\
\text { rectum and } \\
\text { colon }\end{array}$} & $\begin{array}{l}\text { Mainly rectum and } \\
\text { right colon }\end{array}$ & 3 & $150 / 250$ \\
\hline & $\begin{array}{l}\text { Mainly rectum, also } \\
\text { ileum in } 2 \text { cases } \\
\text { Distribution } \\
\text { unknown }\end{array}$ & $\begin{array}{l}3 \\
\mathbf{I}\end{array}$ & $\begin{array}{l}30 / 80 \\
>50\end{array}$ \\
\hline
\end{tabular}

in the rectosigmoid and in the right side of the colon. Their numbers varied from 30 to 300 . Two patients had a few polyps in the terminal ileum. Adenomatous polyposis coli does not involve the ileum. Adenomatous polyps and juvenile polyps have been reported in the appendix (Shnitka and Sherbaniuk, 1957), though this part of the large gut was not involved in any of our patients with juvenile polyposis as far as this could be ascertained. I. M. P. Dawson (1964, personal communication) carried out a post-mortem examination on a girl of 15 months in whom there was a state of juvenile polyposis throughout the entire gastro-intestinal tract. The cause of death was anaemia due to intestinal haemorrhage.

Congenital anomalies or malformations occurred in 4 patients (see Table II). This has not been described in adenomatous polyposis. Two of the four with congenital anomalies also had low plasma proteins and serum potassium. Both were anaemic. Two other patients not included in this series also had low plasma proteins. One girl of 18 years developed generalized oedema and another aged 8 presented with such gross plasma protein depletion that a prophylactic colectomy had to be performed. In a recent patient admitted to St. Mark's Hospital the presenting symptoms were profound anaemia and prolapse of polyps out of the rectum. This patient, again not included in this series of fully investigated cases, also had a patent interventricular septum. Biochemical abnormalities, in the experience of this hospital, are not a feature of the presenting symptoms of adenomatous polyposis. The features of juvenile and adenomatous polyposis are compared in Table V.

TABLE V

COMPARISON OF JUVENILE AND ADENOMATOUS POLYPOSIS

\begin{tabular}{|c|c|c|}
\hline & Juvenile & Adenomatous \\
\hline $\begin{array}{l}\text { Average age of } \\
\text { onset of } \\
\text { symptoms }\end{array}$ & 6 & 30 \\
\hline Symptoms & $\begin{array}{l}\text { Bleeding; } \\
\text { prolapse; } \\
\text { auto-amputation }\end{array}$ & Diarrhoea \\
\hline $\begin{array}{l}\text { Congenital } \\
\text { anomalies }\end{array}$ & & \\
\hline $\begin{array}{l}\text { Premalignant } \\
\text { Histology }\end{array}$ & $\begin{array}{l}\text { No } \\
\text { Hamartoma }\end{array}$ & $\begin{array}{l}\text { Yes } \\
\text { Neoplasm }\end{array}$ \\
\hline
\end{tabular}

Treatment. The diagnosis of juvenile polyposis should be confirmed on histological examination of several polyps before considering treatment. As far as cancer prevention is concerned radical 
surgery appears to be unnecessary, as there is yet no evidence that juvenile polyps are pre-cancerous. Five patients had radical surgery as it was wrongly assumed at the time that their polyposis was adenomatous and therefore premalignant. Although juvenile polyposis is not thought to have any malignant potential, the loss of blood and protein may be severe enough to warrant a colectomy.

\section{Summary}

The histopathology, clinical features, and family histories of II patients with juvenile polyposis of the large intestine are described.

Juvenile polyposis coli is clinically and pathologically distinct from adenomatous polyposis coli. It usually presents in children with rectal bleeding and prolapse of polyps. Associated congenital abnormalities were found in 4 of the II patients studied.

Juvenile polyposis should be classified among the hamartomatous syndromes. There is no evidence, as yet, that it is a pre-cancerous condition.

In a proportion of cases, there is a family history of juvenile polyposis and/or cancer of the large bowel. Various genetic explanations are discussed, and it is concluded that juvenile polyposis may result from modification of the action of the gene for adenomatous polyposis by an allele received from the normal parent. Isolated cases of juvenile polyposis may be the result of fresh mutations.

We are much indebted to $\mathbf{M r}$. M. H. Harmer, Mr. Rex Lawrie, and the consultant staff of St. Mark's Hospital for permission to study their patients. The photographs were taken by Mr. Norman Mackie. Mr.
Lloyd Soodeen has given valuable technical assistanc. The expenses of this investigation have been provided out of a block grant to the Research Department St. Mark's Hospital from the British Empire Cancer Campaign.

\section{REFERBNCES}

Castro, A. F. (I955). Adenomatous polyps of the rectum and col $\frac{\overline{9}}{2}$ in children. Clin. Proc. Child. Hosp. ((Wash.), 1x, 29.

Creamer, B., Shorter, R. G., and Bamforth, J. (196r). The turnovgr and shedding of epithelial cells. Gut, 2, r 10.

Gastroenterology (1962). Cell renewal in the gastrointestinal tratot of man. 43,472 .

Gordon, D. L., Hallenbeck, G. A., Dockerty, M. B., Kenned采 R. L. J., and Jackman, R. J. (1957). Polyps of the colon in children. Arch. Surg., 75, 90.

Hines, M. O., Hanley, P. H., Ray, J. E., and Rush, B. M. (I95ळ) Polyps of the colon and rectum in children: Experience with cases. Dis. Colon Rect., 2, 161 .

Kerr, J. G. (1948). Polyposis of the colon in children. Amer. Surg., 76, 667.

Knox, W. G., Miller, R. E., Begg, C.F., and Zintel, H. A. (1960). Juvenile polyps of the colon. Surgery, 48, 201 .

Lane, J. R. (1865). Clinical observations on diseases of the rectur. Lancet, $2,87$.

Leblond, C. P., and Stevens, C. E. (1948). The constant renewal of the intestinal epithelium in the albino rat. Anat. Rec., roo, $357 . \bar{B}$ Mallam, H. S., and Thomson, S. A. (1959). Polyps of the rectufin and colon in children. Canad. $\mathcal{~}$. Surg., 3, 17.

Marks, M. M., and Atkinson, K. G. (1964). Heterotopic bone in juvenile rectal polyp. Dis. Colon Rect., 7, 345 .

McColl, I., Bussey, H. J. R., Veale, A. M. O., and Morson, B. F (1964). Juvenile polyposis coli. Proc. roy. Soc. Med., 57, 896. O

Morson, B. C. (1962a). Some peculiarities in the histology of intestinal polyps. Dis. Colon Rect., 5, 337.

- (1962b). Precancerous lesions of the colon and rectum. Amer. med. Ass., 179, 316.

Roth, S. I., and Helwig, E. B. (I963). Juvenile polyps of the cols and rectum. Cancer, $16,468$.

Shnitka, T. K., and Sherbaniuk, R. W. (1957). Adenomatoos8 polyps of the appendix in children. Gastroenterology, 32, 462. Q

Todd, I. O. (1963). Juvenile polyps. Proc. roy. Soc. Med., 56, 96

Veale, A. M. O. (1962). Familial intestinal polyposis. Ph. Thesis, University of London.

- (1965). Intestinal Polyposis Eugenics Laboratory Memoin Series, 40. Cambridge University Press, London

Willis, R. A. (1958). The Borderland of Embryology and Pathology. Butterworth, London. 